\title{
THE EFFICACY AND SAFETY OF CERVICAL SPINE IMMOBILIZATION IN ELDERLY PATIENTS WITH CERVICAL SPINE FRACTURES: A SYSTEMATIC REVIEW
}

\author{
S. Epton, R. Preece, D. Hay, M. kaminaris, D. Lui, \& A. Trompeter. \\ Trauma and Orthopaedics Department, Saint George's University Hospital, London, UK.
}

\begin{abstract}
As both life expectancy and average population age continue to rise, so too does the incidence of cervical spine (c-spine) injuries. C-spine fractures are associated with high morbidity and mortality, but the question is how best to treat them?

This review is to compare the safety and efficacy of c-spine immobilisation in a rigid collar with other treatment modalities in elderly population. Available literature was reviewed to determine how treatment efficacy is assessed, with particular focus on whether osseous union or fibrous non-bony union should be considered as a successful outcome.

This study was designed in accordance with PRISMA guidelines. Pubmed/Medline databases were selected for analysis.

When considering patients over the age of 65 , it is unclear whether management with a collar is safer than operative management or immobilisation with HALO vest. However, amongst studies that further subdivide elderly patients according to age there is more of a consensus; it appears that in those under the age of 75, operative management is safer, whereas in those over the age of 85 , immobilisation in a collar is associated with lower mortality rates. Between the ages of $75-85$ there is less clarity. Osseous union occurs more commonly in patients managed operatively, but fibrous non-bony union was not associated with any adverse outcomes in these studies.

Conclusion: At present, there are no randomised controlled trials that have tried to delineate whether management in a collar is safer or more effective than other treatments such as HALO vest or operative fixation. However, evidence from various cohort studies does suggest that "elderly" patients with c-spine fractures should not be considered as one homogenous cohort, but should instead be subdivided according to age. Interestingly, these studies suggest that fibrous non-bony union may be an adequate treatment outcome in older. Further research into this complex field is required.

Keywords: Trauma, elderly care, spinal fractures, treatment outcome, survival rate
\end{abstract}

\section{Introduction}

Dreviously, the majority of trauma was highly sustained by young patients, but now those presenting to major trauma centres are elderly patients following low energy accidents ${ }^{1,2}$. In 2015, Kehoe et al. predicted that if current trends continue, over-75s will soon represent the largest single group of major trauma patients in the $\mathrm{UK}^{2}$.

The frequency of cervical-spine (cspine) fractures in the elderly trauma population remains relatively low compared to those of the upper and lower trunk. Baidwan et al. found that for the geriatric population, there has been a significantly greater increase in the incidence of fractures in the neck than in other areas of the body ${ }^{3}$. The c-spine, particularly the odontoid peg is thought to be particularly susceptible to injury in this age group due to both osteopenia and degenerative change ${ }^{4}$. This is of considerable clinical importance as the survival rate of elderly major trauma patients with c-spine fractures is markedly lower than other general trauma patients of the same age $(21 \%$ and $10 \%$ respectively) $)^{5}$.

Because of the increase in c-spine fractures and their poor prognosis, the 
management of these injuries has been a matter of debate. Currently both conservative and surgical methods are employed to manage c-spine fractures. The most widely used conservative methods are rigid cervical collar immobilisation (e.g. Miami-J) and halovest. Surgical treatment varies depending on the spinal level and fracture morphology and is most commonly used in patients with unstable or displaced fractures. Post-operatively, some surgically managed patients are also immobilized in a collar ${ }^{6}$.

The choice of management of c-spine fractures is a complex one, with conflicting advice in the literature and relatively high mortality rates regardless of the treatment modality employed. For this reason, the aim of this systematic review is; to review the efficacy and safety of cervical collars in comparison to other treatment modalities in elderly patients, to review the of cervical collars in comparison to other treatment modalities in elderly patients.

\section{Material and methods}

The systematic review protocol was designed in accordance with the PRISMA statement. A search of the MEDLINE database in January 2019 was independently conducted by two investigators using the statements; cervical spine injury or fracture, management or immobilisation, elderly or geriatric or over 65 . The initial search elicited 2,035 results, of which 14 were included in this final review.

Inclusion criteria: The research quantitatively or qualitatively compares the efficacy and/or safety of c-spine collar and other treatment modalities in managing c-spine fractures, the complete, and peer-reviewed manuscript must be available online.

Exclusion Criteria: Animal studies, papers not available in English, initial studies that have been re-reported with longer follow-up or had participants that formed parts of larger cohorts in other studies, papers with fewer than 30 patients, and papers published more than 20 years ago.

The following important characteristics were noted for analysis of each paper: principal author, year of publication, study design, c-spine fracture type, number of participants, age range of study participants, method of efficacy analysis, collar efficacy and safety compared to other management options, and rates and subsequent risks of collar non-compliance.

\section{Results}

The initial search produced 2035 results; of which 14 were included in the final review based on both the inclusion and exclusion criteria (figure 1).

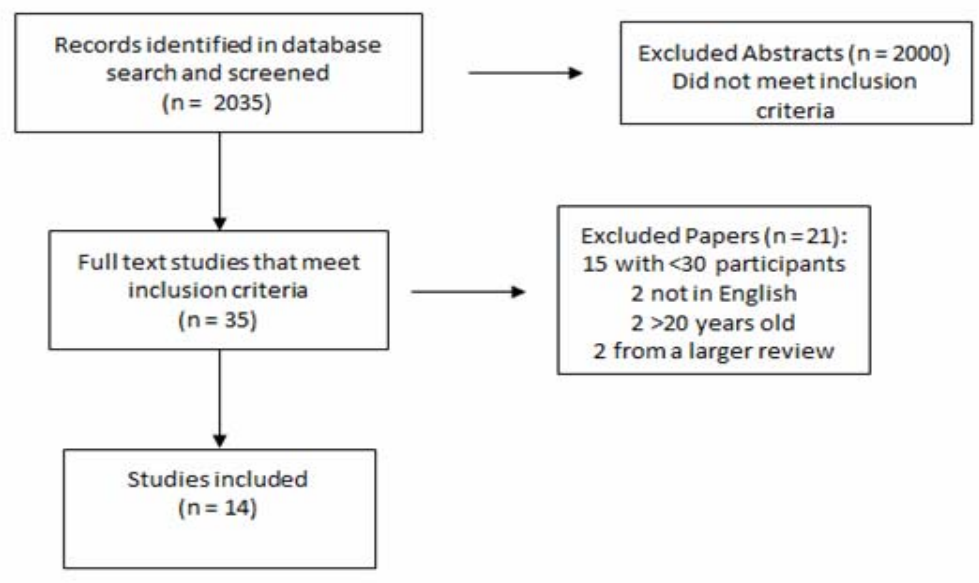

Figure 1. PRISMA Flow Diagram 
Study characteristics are summarised in table 1. Of the 14 papers, 3 included all Cspine fractures and the other 11 included odontoid fractures only. Treatment efficacy and safety are summarised in tables 2 and 3 respectively.

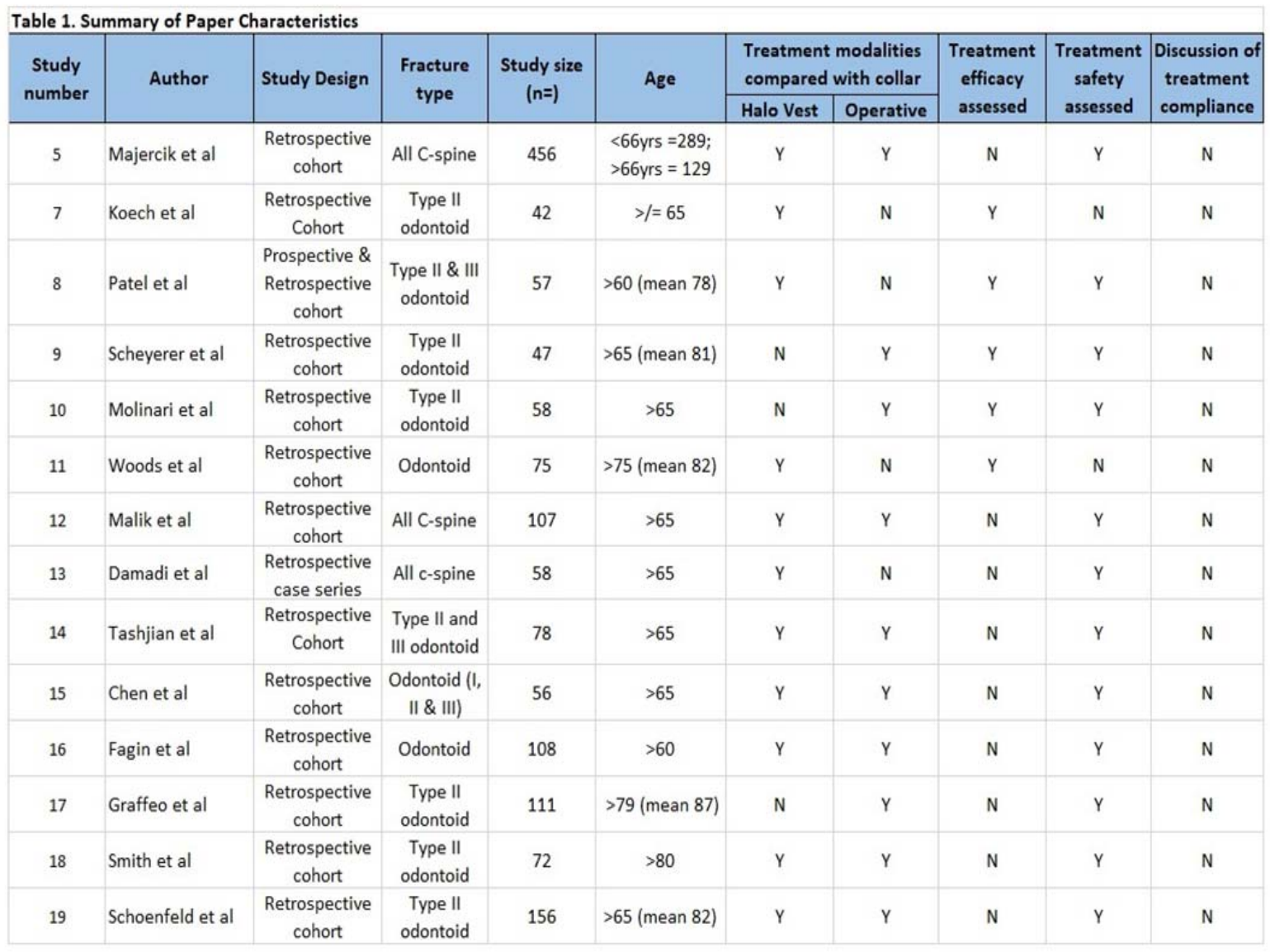

\begin{tabular}{|c|c|c|c|c|c|c|c|}
\hline \multirow{2}{*}{$\begin{array}{l}\text { Study } \\
\text { number }\end{array}$} & \multirow{2}{*}{ Author } & \multirow{2}{*}{$\begin{array}{l}\text { Outcome } \\
\text { measure* }\end{array}$} & \multicolumn{3}{|c|}{ Result } & \multirow{2}{*}{$\begin{array}{c}\text { Significant } \\
(p<0.05)\end{array}$} & \multirow{2}{*}{$\begin{array}{c}\text { Adverse } \\
\text { effect of } \\
\text { FNBU? }\end{array}$} \\
\hline & & & Collar & Halo vest & Operative & & \\
\hline 7 & Koech et al & FS \& OU & $\begin{array}{l}F S=90 \% \\
O U=50 \%\end{array}$ & $\begin{array}{l}F S=100 \% \\
O U=37.5 \%\end{array}$ & - & - & - \\
\hline 8 & Patel et al & $\begin{array}{l}\text { FS, OU \& } \\
\text { FNBU }\end{array}$ & $\begin{array}{l}F S=90 \% \\
O U=46.7 \% \\
F N B U=43.3 \%\end{array}$ & $\begin{array}{l}\mathrm{FS}=62.5 \% \\
\mathrm{OU}=54.2 \% \\
\mathrm{FNBU}=8.3 \%\end{array}$ & - & $\mathrm{N}$ & $\mathrm{N}$ \\
\hline 9 & Scheyerer et al & OU & $0 \%$ & - & $\begin{array}{l}\mathrm{ASF}=23 \% ; \mathrm{PF}= \\
94 \% * *\end{array}$ & Y & $\mathrm{N}$ \\
\hline 10 & Molinari et al & OU \& FNBU & $\begin{array}{l}\mathrm{OU}=6 \% \\
\text { FNBU }=33 \%\end{array}$ & - & $\begin{array}{l}\mathrm{OU}=28 \% \\
\text { FNBU }=100 \%\end{array}$ & Y & $\mathrm{N}$ \\
\hline 11 & Woods et al & FNBU & $28.5 \%$ & $27 \%$ & $5 \%$ & $Y$ & - \\
\hline
\end{tabular}




\begin{tabular}{|c|c|c|c|c|c|c|c|c|c|}
\hline \multirow{2}{*}{$\begin{array}{l}\text { Study } \\
\text { number }\end{array}$} & \multirow{2}{*}{ Author } & \multirow{2}{*}{ Outcome measure } & \multicolumn{2}{|c|}{ Collar } & \multicolumn{2}{|c|}{ Halo Vest } & \multicolumn{2}{|c|}{ Operative } & \multirow{2}{*}{ Significant $(p<0.05$} \\
\hline & & & Morbidity & Mortality & Morbidity & Mortality & Morbidity & Mortality & \\
\hline 5 & Majercik et al & Mortality & - & $12.0 \%$ & - & Halo $=40 \%$ & - & $6.0 \%$ & $Y$ \\
\hline 8 & Patel et al & Mortality & - & $10 \%$ & - & $12.5 \%$ & - & - & $\mathrm{N}$ \\
\hline 9 & Scheyerer et al & Mortality & - & $85 \%$ & - & - & - & $\begin{array}{c}\text { ASF }=20 \% \\
P F=27.7 \% * *\end{array}$ & $Y$ \\
\hline 10 & Molinari et al & $\begin{array}{l}\text { Morbidity \& } \\
\text { Mortality }\end{array}$ & $6 \%$ & $12.5 \%$ & - & - & $12.5 \%$ & $20 \%$ & - \\
\hline 12 & Malik et al & In hospital mortality & - & $13.4 \%$ & - & $8 \%$ & - & $8.3 \%$ & - \\
\hline 13 & Damadi et al & Mortality & - & $23 \%$ & - & $29 \%$ & - & - & $\mathrm{N}$ \\
\hline 14 & Tashjian et al & Mortality & - & $26 \%$ & - & $40 \%$ & - & $0 \%$ & $\begin{array}{c}\text { Halo v. non-halo }=Y \\
\text { Halo } v \text { collar }=N\end{array}$ \\
\hline 15 & Chen et al & $\begin{array}{c}\text { Morbidity; } \\
30 \text { day mortality; } \\
\text { median long-term } \\
\text { survival, HLOS }\end{array}$ & $25 \%$ & $30 d=7.1 \%$ & - & - & $17.9 \%$ & $30 d=3.6 \%$ & $\mathrm{~N}$ \\
\hline 16 & Fagin et al & $\begin{array}{c}\text { Morbidity, Mortality, } \\
\text { HLOS \& Ventillator } \\
\text { days }\end{array}$ & $25 \%(\mathrm{DVT}=2.9 \%)$ & $17.6 \%$ & - & - & $\begin{array}{c}50 \% \text { (DVT }= \\
17.6 \%)\end{array}$ & $\begin{array}{c}8.7 \% \& 11.7 \% \\
\text { (early and late } \\
\text { operative } \\
\text { groups) }\end{array}$ & $\mathrm{N}$ (except for DVT) \\
\hline 17 & Graffeo et al & $\begin{array}{c}\text { Mortality (in } \\
\text { hospital, 30d \& 1yr) }\end{array}$ & - & $\begin{array}{c}\text { In hosp. }=12 \% ; \\
\begin{aligned} \begin{aligned} 30 \mathrm{~d} & =27 \% \quad 1 \mathrm{yr} \\
& =41 \%\end{aligned}\end{aligned}\end{array}$ & - & - & - & $\begin{array}{l}\text { In hosp. }=18 \% ; \\
\begin{aligned} 30 \mathrm{~d} & =24 \% ; \quad 1 \mathrm{yr} \\
& =41 \%\end{aligned}\end{array}$ & $\mathrm{~N}$ \\
\hline 18 & Smith et al & $\begin{array}{c}\text { Morbidity, Mortality } \\
\& \text { HLOS }\end{array}$ & $33 \%$ & $15 \%^{*}$ & $50 \%$ & $15 \%^{*}$ & $62 \%$ & $12 . .5 \%$ & $\begin{array}{l}\text { Morbidity }=Y \\
\text { Mortality }=N\end{array}$ \\
\hline 19 & Schoenfeld et al & $\begin{array}{c}\text { Mortality (3 months } \\
\& 1 y r)\end{array}$ & - & $\begin{array}{c}3 \text { months }=26 \% \\
1 y r=36 \%\end{array}$ & - & $\begin{array}{c}3 \text { months }=21 \% \\
1 y r=32 \%\end{array}$ & - & $\begin{array}{c}3 \text { months }=11 \% \\
1 y r=21 \%\end{array}$ & $Y$ (only under $75 Y 0$ ) \\
\hline
\end{tabular}

Koech et al. observed that osseous union occurred in $50 \%$ of patients treated in collars and in $37.5 \%$ of patients managed with a halo. However, clinically stable union, with either osseous union or fibrous non-bony union (FNBU), was achieved in $90 \%$ of those in a collar and $100 \%$ those in a halo ${ }^{7}$. Patel et al. also found no significant difference in the rate of clinically stable union between patients managed with a halo or a collar ${ }^{8}$. Koech and Patel found that $4.8 \%$ and $10 \%$, respectively, went on to require operative fixation due to unstable non-union. No patients with FNBU developed myelopathy.

All of the studies that compared collar and operative management found that operatively managed patients demonstrated higher rates of osseous union $^{9-11}$. Malik did not differentiate between collar and halo in the 'nonsurgical' cohort but again found an increased rate of osseous union in patients managed operatively compared to conservatively $\quad(100 \%$ and $80 \%$ respectively) ${ }^{12}$. Interestingly, despite the lower rate of osseous union, Molinari et al. found slightly lower neck disability index and analogue pain scores in collar group compared to operative group ${ }^{10}$. Furthermore, no adverse outcomes were associated with FNBU at follow-up ${ }^{9,10}$.

Studies with elderly patients $(>60)$ and no further subdivision according to age: Scheyerer found that patients managed with a collar had a significantly reduced survival rate at a follow-up compared to those managed operatively 9 . In contrast, Molinari found that those managed operatively had higher mortality $(20 \% \mathrm{v}$. $12.5 \%)$ and complication rates $(24 \% \mathrm{v}$. $6 \%$ ), although formal statistical analysis was not conducted. Collar group complications were limited to two patients who developed significant skin breakdown in the neck region from prolonged full-time cervical collar wear $(6 \%)^{10}$. When comparing collar to halo, Damadi et al. found that there was no 
significant difference between mortality rates $(23 \%$ and $29 \%$ respectively). Mortality correlated most strongly with the Injury Severity Score (ISS) ${ }^{13}$. Conversely, Tashjian et al. found that both the morbidity and mortality rates of patients with type II and III odontoid fractures were significantly higher in those treated with halo vests compared to collars $(66 \%$ vs. $36 \%$ morbidity; $42 \%$ vs. $20 \%$ mortality $)^{14}$. The risk of both pneumonia and cardiac arrest was also significantly higher in those wearing a halo. Whilst Malik et al. noted that total study in-hospital mortality was $11.2 \%$ they did not assess whether the difference between collar, halo and operative management reached statistical significance ${ }^{12}$.

When comparing patients managed with either collar or operatively, Chen et al. found that there was no significant difference in complication rate and median long-term survival, but that operative patients had a significantly longer hospital length of stay. Common complications included deep venous thrombosis, pulmonary embolism $(10.7 \%)$, pneumonia, new neurological deficits, and necessitation of reintubation $(7.1 \% \text { each })^{15}$.

Fagin et al. split 108 patients into three cohorts; 'early operative' ( $<3$ days postinjury), 'late operative' ( $>3$ days postinjury) and non-operative. The assisted feeding, morbidity and mortality rate between the three groups were not significantly different, however, there were significantly fewer DVTs in the conservatively managed group $(\mathrm{p}=0.02)$. The percentage of patients discharged to a skilled nursing facility was similar among all three groups. The operatively managed groups had significantly more ventilator days and longer HLOS ${ }^{16}$.

Studies of patients aged 75 and over; Graffeo et al. found that overall mortality following type II odontoid fracture was $26 \%$ at 30 days, and $41 \%$ at 1 year. However, there was no significant difference in mortality rates between those managed in a collar versus those managed operatively ${ }^{17}$. On the other hand, Smith et al. found that for patients with type II odontoid fracture, HLOS and number of complications per person was significantly higher in the operative group. The rate of major complications was also higher in those managed operatively, but did not reach statistical significance. Within the conservatively managed group, those treated with a halo vest were significantly more likely to develop airway compromise (including respiratory distress, pneumonia or intubation) than those treated with a collar $^{18}$.

Woods et al. did not differentiate between collar and halo in the nonoperative group, but it is worth noting that at 3 months there was a significantly lower mortality rate in the conservatively managed group, but at 1 and 5 years there was no longer a significant difference. A higher Charlson Co-morbidity Index (CCI) was associated with higher mortality in both operatively and nonoperatively managed patients. There was a high rate of complications in both groups $(37.5 \%$ and $47 \%$, respectively) including persistent dysphagia, wound, pin site infection, stiffness and skin irritation $^{11}$.

Studies comparing differences in outcome between different age subgroups within the elderly population; Schoenfeld et al. found that in patients with type II odontoid fractures, overall mortality was $10 \%$ in hospital, $21 \%$ at 3 months and $31 \%$ at one year. At 3 months mortality was significantly associated with age $(6 \%$ mortality in $65-74$ year olds v. $18 \%$ mortality at 75-84 years old and $34 \%$ in the over $85 \mathrm{~s}$ ) but by one year this was no longer significant. Across the entire population, non-operative management had a non-significantly higher rate of mortality than operative management. There was no difference in mortality rates between halo and collar. 
The CCI was found not to be significantly associated with mortality when adjusted for confounding factors. When the population was sub-divided according to age, Cox regression modelling showed that a protective effect of surgery was seen in patients aged 65 to 74 years, for whom the hazard ratio associated with surgery for mortality after odontoid fracture was 0.4 (95\% CI: $0.1-1.5)$. Those aged 75 to 84 years had a hazard ratio of 0.8 (95\% CI: $0.3-2.3$ ), and patients 85 years or older had a hazard ratio of 1.9 (95\% CI: 0.6-6.1) ${ }^{19}$.

Majercik et al. split 456 patients with cspine fractures into two cohorts; 289 'young' (<66 years) and 129 'old' (66 years and above). The 'old' cohort had a higher mortality rate, despite having a lower ISS than their 'young' counterparts. Irrespective of age, Glasgow Coma Scale or ISS, mortality was higher in those managed with a halo than either those managed with operative fixation or a collar. The rate of mortality in those managed with a halo was significantly higher in the 'old' group compared to the 'young' one $(40 \%$ vs. $2 \%, p<0.001)$. Conversely, there was no difference in mortality rates between the 'old' and 'young' operative and collar subgroups ${ }^{5}$.

\section{Discussion}

Morbidity and mortality rates among elderly patients with c-spine injuries are higher than those within the general geriatric trauma population ${ }^{1}$. In the papers included in this study, in-patient mortality rates ranged from $10-31 \%$ and 30 day mortality ranged from $5.3-26 \%{ }^{14,15,17,19}$. The incidence of mortality begins to fall by 1 year post-injury but is still reported to be as high as $41 \%{ }^{17}$. These findings concur with those of van Middendorp et al, who systematically reviewed mortality rates in elderly patients with c-spine fractures and found them to range from $6.45-34.3 \%$ by long-term follow-up, with the majority of the deaths occurring by short-term follow-up ${ }^{20}$.
Irrespective of injury severity or treatment modality, patient age is correlated with the risk of both complications and mortality in all 3 studies that investigated its effects ${ }^{5,14,19}$. The lowest mortality rates were seen in studies with 'younger' elderly populations, whereas the highest rates of $26 \%$ at 30 days and $41 \%$ at 1 year, were in a study of patients aged 80 and above $e^{14,15,19}$.

Comparing mortality rates across the individual studies was hindered by the wide variation in the time to follow-up. Whilst some of the literature provided specific time frames (i.e. 30 day mortality), others only reported a nonspecific 'maximal follow-up'. In one instance, this ranged from 1-77 months, making it difficult to draw meaningful comparisons between this paper and others ${ }^{9}$.

Treatment safety: Whilst age is known to be a significant risk factor, it is not the sole predictor of c-spine fracture outcomes. The various treatment modalities available are known to have significant differences in safety and efficacy in the elderly population. However, drawing conclusions about the most suitable treatment for these patients has previously been difficult due to the heterogeneity of the evidence available. Of the studies that investigated morbidity and mortality rates in those treated with a collar compared with surgical intervention, 3 found surgery to be associated with better outcomes ${ }^{9,14,19}, 2$ found management with a collar to be significantly better ${ }^{5,18}$, and 3 found no statistical difference ${ }^{15-17}$. Two studies did not assess the significance of their results $^{10,12}$. This appears to reinforce the consensus that there is too greater variance in the published literature to recommend either collar or operative management.

However, when papers categorise patients based on their age, higher rates of concordance are demonstrated. Both 
studies of patients over the age of 75 found that conservative management was associated with lower mortality ${ }^{11,17}$. Similarly, Schoenfeld et al. found that whilst surgical management is safer in those under the age of 75 , by 85 years of age it is more hazardous than conservative treatment ${ }^{19}$. These findings are supported by Barlow et al. who used analytic modelling to compare Quality Adjusted Life Years (QALY) and cost effectiveness of conservative versus operative management of type II odontoid fractures. They found that QALY were higher in operatively managed patients up until the age of 85. After this, QALY was higher in patients managed conservatively. Across all age groups operative management was more costly ${ }^{21}$.

Several studies specifically compared the halo-vest to cervical collars and/or surgical treatment. Three out of 6 found the halo vest to be associated with significantly higher rates of complications and mortality than other management options $^{5,14,18}$; the other 3 found no significant difference ${ }^{8,13,19}$. No studies found the halo to be safer than either collar or operative management. Tashjian et al. found that the complication rate of those patients managed with a halo is as high as double that of those managed in either a collar or operatively $(42 \% \mathrm{v}$. $20 \%)^{14}$. Majercik et al. demonstrated that as age increases the risks associated with halo management are even greater ${ }^{5}$. The most common complications in patients managed with halo-vests were respiratory compromise secondary to aspiration or pneumonia and acute cardiac events $^{5,13,14,18}$.

Efficacy of collars: Rates of bony union in operatively managed patients ranged varied widely (23-94\%), as did those of patients managed in a collar $(0-50 \%)^{7,9}$. Of those fractures that do not demonstrate osseous union, many go on to achieve stable $\mathrm{FNBU}^{7,8,10,11}$. Koech et al. found that whilst osseous union only occurred in $50 \%$ of patients treated in collars and in
$37.5 \%$ of patients managed with a halo, fracture stability was achieved in $90 \%$ and $100 \%$ respectively ${ }^{7}$. Previously FNBU was seen as an unsuccessful outcome due to the risk of subsequent myelopathy, as described by Anderson and D'Alonzo ${ }^{22}$. However, there were no adverse effects (including myelopathy, a deterioration in the neck disability index or pain analogue scale) associated with FNBU in the 4 studies that described it $^{7,8,10,11}$. Given these findings, stable FNBU may be an acceptable treatment outcome in elderly patients with c-spine fractures.

Limitations: The main limitation when comparing the different management options for c-spine fractures in the existing literature is that the majority of studies simply define patient cohorts as non-operative or operative. The nonoperative cohort often consists of patients managed with both collar and halo, and the operative group may include different surgical approaches. Given that the morbidity and mortality data for collar and halo are often markedly different, grouping them together reduces the validity of any comparison with other management modalities. The same is true for those studies that compare the halo device to a combined cohort of collar and operatively managed patients. Currently no large scale randomised controlled trials specifically comparing collar, halo and the different operative management options exists. This reduces the value of any conclusions that can be drawn from the current literature.

Conclusion: Morbidity and mortality rates in elderly patients with c-spine injuries are high. When those over 65 years of age are considered as one cohort, there is conflicting evidence as to which treatment modality is best. However, when separated into age subgroups, the current literature becomes more homogenous. It suggests that those under the age of 75 should be offered operative management and those over the age of 85 
should be managed conservatively. However, between the ages of 75-85 there is still a lack of consensus. A randomised controlled trial providing further delineation of treatment modality, stratified by age, is needed to draw definitive conclusion.

Throughout all age groups operative management is associated with the highest rate of osseous union. However, there is no evidence to suggest that FNBU is associated with poorer short- term outcomes it this age group. The majority of the literature currently available is retrospective, with small participant numbers and short follow-up times. For this reason, further prospective studies comparing cervical collars and operative management over longer follow-up periods are needed to provide conclusive evidence regarding the risk of adverse outcomes in patients with FNBU.

\section{References}

1. Krug. EG SG, Lozano. R. The global burden of injuries. American Journal of Public Health. 2000;90:523-6.

2. Kehoe A, Smith JE, Edwards A, Yates D, Lecky F. The changing face of major trauma in the UK. Emerg Med J.

2015;32:911-5

3. Baidwan NK, Naranje SM. Epidemiology and recent trends of geriatric fractures presenting to the emergency department for United States population from year 2004-2014. Public Health. 2017;142:64-9.

4. Watanabe M, Sakai D, Yamamoto Y, Sato M, Mochida J. Upper cervical spine injuries: age-specific clinical features. J Orthop Sci. 2010;15:485-92.

5. Majercik S, Tashjian RZ, Biffl WL, Harrington DT, Cioffi WG. Halo vest immobilization in the elderly: a death sentence? J Trauma. 2005;59:350-6; discussion 6-8.

6. Delcourt T, Bégué T, Saintyves G, Mebtouche N, Cottin P. Management of upper cervical spine fractures in elderly patients: current trends and outcomes. Injury. 2015;46 Suppl 1:S24-7.

7. Koech F, Ackland HM, Varma DK, Williamson OD, Malham GM. Nonoperative management of type II odontoid fractures in the elderly. Spine (Phila Pa 1976). 2008;33:2881-6.

8. Patel A, Zakaria R, Al-Mahfoudh R, Clark S, Barrett C, Sarsam Z, et al. Conservative management of type II and III odontoid fractures in the elderly at a regional spine centre: A prospective and retrospective cohort study. $\mathrm{Br} \mathrm{J}$ Neurosurg. 2015;29:249-53.

9. Scheyerer MJ, Zimmermann SM, Simmen HP, Wanner GA, Werner CM. Treatment modality in type II odontoid fractures defines the outcome in elderly patients. BMC Surg. 2013;13:54.

10. Molinari W, Khera O, Gruhn W, Molinari RW. Functional outcomes, morbidity, mortality and fracture healing rates in 58 consecutive geriatric odontoid fracture patients treated with cervical collar or posterior fusion. Evid Based Spine Care J. 2011;2:55-6.

11. Woods BI, Hohl JB, Braly B, Donaldson W, Kang J, Lee JY. Mortality in elderly patients following operative and nonoperative management of odontoid fractures. J Spinal Disord Tech. 2014;27:321-6.

12. Malik SA, Murphy M, Connolly P, O'Byrne J. Evaluation of morbidity, mortality and outcome following cervical spine injuries in elderly patients. Eur Spine J. 2008;17:585-91.

13. Damadi AA, Saxe AW, Fath JJ, Apelgren KN. Cervical spine fractures in patients 65 years or older: a 3-year experience at a level I trauma center. J Trauma. 2008;64:745-8.

14. Tashjian RZ, Majercik S, Biffl WL, Palumbo MA, Cioffi WG. Halo-vest immobilization increases early morbidity and mortality in elderly odontoid fractures. J Trauma. 2006;60:199-203.

15. Chen YR, Boakye M, Arrigo RT, Kalanithi PS, Cheng I, Alamin T, et al. Morbidity and mortality of C2 fractures in the elderly: surgery and conservative treatment. Neurosurgery. 2012;70:1055-9; discussion 9.

16. Fagin AM, Cipolle MD, Barraco RD, Eid S, Reed JF, Li PM, et al. Odontoid fractures in the elderly: should we operate? J Trauma. 2010;68:583-6.

17. Graffeo CS, Perry A, Puffer RC, Carlstrom LP, Chang W, Mallory GW, et al. Deadly falls: operative versus nonoperative management of Type II odontoid process fracture in octogenarians. J Neurosurg Spine. 2017;26:4-9.

18. Smith HE, Kerr SM, Maltenfort M, Chaudhry S, Norton R, Albert TJ, et al. Early complications of surgical versus conservative treatment of isolated type II odontoid fractures in octogenarians: a retrospective cohort study. J Spinal Disord Tech. 2008;21:535-9.

19. Schoenfeld AJ, Bono CM, Reichmann WM, Warholic N, Wood KB, Losina E, et al. Type II odontoid fractures of the cervical spine: do treatment type and medical comorbidities affect mortality in elderly patients? Spine (Phila Pa 1976). 2011;36:879-85

20. van Middendorp JJ, Albert TJ, Veth RP, Hosman AJ. Methodological systematic review: mortality in elderly patients with cervical spine injury: a critical appraisal of the reporting of baseline characteristics, follow-up, cause of death, and analysis of risk factors. Spine (Phila Pa 1976). 2010;35:1079-87.

21. Barlow DR, Higgins BT, Ozanne EM, Tosteson AN, Pearson AM. Cost Effectiveness of Operative Versus NonOperative Treatment of Geriatric Type-II Odontoid Fracture. Spine (Phila Pa 1976). 2016;41:610-7.

22. Anderson LD, D'Alonzo RT. Fractures of the odontoid process of the axis. J Bone Joint Surg Am. 1974;56:166374. 